\title{
CULTURA, PATRIMÔNIO E MUSEU NO PORTO MARAVILHA
}

\author{
Leopoldo Guilherme Pio ${ }^{1}$
}

RESUMO: Nesse texto, apresentamos uma análise preliminar dos significados e funções das ações culturais propostas no projeto de revitalização da Zona Portuária do Rio de Janeiro, denominado "Porto Maravilha". Destacamos os usos da categoria "cultura", as políticas propostas para o Museu do Amanhã e o MAR (Museu de Arte do Rio) e a importância atribuida ao patrimônio local. Destacamos algumas das questões abordadas em nossa pesquisa de doutorado, cujo objetivo é compreender o uso do patrimônio cultural e das ações culturais na revitalização da Zona Portuária do Rio de Janeiro.

PALAVRAS-CHAVE: Cultura; museu; patrimônio; zona portuária.

Recebido em: outubro de 2012 Aceito em: março de 2013

Para citar este artigo:

PIO, Leopoldo; Cultura, patrimônio e museu no Porto Maravilha. In: Revista Intratextos, 2013, vol 4, no1, p. 8-26. DOI: 10.12957/intratextos.2013.8565

\footnotetext{
${ }^{1}$ Leopoldo Guilherme Pio é doutorando do Programa de Pós-graduação em Ciências Sociais (PPCIS/UERJ) e pesquisador do Núcleo Estudos Urbanos e Percepções do Ambiente. Email: leoguiller@yahoo.com.br
} 


\section{Introdução}

Nesse texto, fazemos uma análise dos significados e funções das ações culturais propostas no projeto de revitalização da Zona Portuária do Rio de Janeiro, denominado "Porto Maravilha". Destacamos algumas das questões abordadas em nossa pesquisa de doutorado, cujo objetivo é compreender o uso do patrimônio cultural e das ações culturais na revitalização da Zona Portuária do Rio de Janeiro.

Nas últimas décadas, as expressões da memória urbana (marcos históricos, monumentos e patrimônio artístico e histórico) e a "cultura urbana" (englobando um conjunto de valores e estilos de vida de uma coletividade e as expressões esteticas ou artísticas) têm sido utilizados como importantes dinamizadores econômicos e sociais nos projetos de revitalização das áreas urbanas centrais, particularmente nas zonas portuárias (BROUDEHOUX 2011, DEL RIO 2010, ARANTES 2000). Diversos exemplos recentes de revitalização cultural de centros urbanos podem ser citados, tanto no exterior (Convent Garden em Londres, South Seaport em Nova York, Puerto Madero na Argentina) quanto no Brasil (São Luiz do Maranhão, Vitória, São Paulo, entre outros). Apesar das possíveis diferenças entre tais projetos, pode-se perceber certos padrões de intervenção, especialmente no que diz respeito ao papel das atividades culturais na recuperação dos espaços públicos, no intuito de modernizar ou "reinventar" a imagem das cidades. Entre as ações culturais ${ }^{2}$ mais comuns, destacam-se a valorização das tradições locais e da cultura popular, a instalação de museus e centros culturais monumentais, a preservação do patrimônio cultural e arquitetônico, o incentivo a eventos (conferências, festivais, mostras culturais) e o estímulo ao turismo de cunho cultural.

Na medida em que a patrimonialização e revitalização dos centros urbanos tornam-se recursos cada vez mais freqüentes na reestruturação urbana, as áreas históricas revitalizadas tornam-se metáforas de uma nova cidade que se quer construir. A partir da análise das estratégias e discursos presentes em tais iniciativas, pretendemos perceber de que maneira valores e bens culturais são utilizados na legitimação e orientação dos projetos de revitalização, bem como na reelaboração da imagem da cidade do Rio de Janeiro. Convém lembrar que a cidade depende de uma transformação material e simbólica no sentido de se adaptar aos mega eventos que ocorrerão em 2014 (Copa do mundo) e 2016 (Olimpíada). A

\footnotetext{
${ }_{2}^{2}$ Por "ação cultural", compreendo os procedimentos envolvendo recursos materiais e humanos que visam materializar os objetivos de determinada politica cultural. (Coelho 1999, p. 32).
} 
zona portuária possui um papel fundamental nesta reinvenção da cidade, como demonstra o slogan do projeto - "uma nova cidade está nascendo".

O Projeto Porto Maravilha possui quatro frentes de atuação: o estímulo ao uso habitacional, a melhoria na infraestrutura (saneamento, malha viária, meio ambiente), comércio e indústria e cultura e entretenimento. Embora não se possa descartar a importância das três primeiras, é possível notar que as atividades culturais são vistas por políticos e pela opinião pública como aspecto central e determinante do sucesso da revitalização econômica e social de espaços urbanos "degradados". Entre as principais iniciativas do Porto Maravilha em sua primeira fase, destacam-se a revitalização da Praça Mauá e do Píer Mauá, a reurbanização do Morro da Conceição (com melhorias nas vias locais, rede elétrica e restauração de patrimônio histórico); a instalação de equipamentos culturais (Museu do Amanhã e o Museu de Arte do Rio, entre outros), a recuperação de edificações de valor histórico (por exemplo, o edifício do Jornal $A$ Noite). Nesse sentido, vale lembrar que nosso objeto de pesquisa é um projeto urbano ainda em curso, isto é, um conjunto de diretrizes e propostas que não foram efetivadas completamente.

Cabe lembrar que intervenções urbanas não devem ser interpretadas apenas como meios de transformação na estrutura material ou na lógica econômica da cidade, mas igualmente enquanto projetos que sugerem um certo ethos ou código social, bem como um certo ideal do que a cidade é ou deve ser. Assim, a partir dos processos de reestruturação material e simbólica da cidade, formula-se uma "imagem urbana", isto é, um "sistema de ordem que comunica um código, um modo de entender, avaliar e valorizar a cidade" e que “(...) no nível simbólico, corresponde a uma didática que ensina o que é e quem é na cidade" (FERRARA 2000, p. 45-6). Nesse sentido, através de grandes reformas urbanas se estabelecem valores e representações que estimulam determinadas formas de vida urbana. Determinadas noções de "civilização", "progresso" e "modernidade" são disseminadas, práticas culturais específicas são disseminadas, e uma ideia de "ordem pública" é legitimada. Nesse sentido, termos como revitalização, patrimônio e centro histórico não são utilizados de modo puramente objetivo ou neutro, mas refletem visões de mundo e formas de autoconsciência (Gonçalves 2002).

Para dar conta dessas imagens e valores construídos pelo projeto, desenvolvemos uma pesquisa documental, tendo como principal fonte o "Estudo de Impacto de Vizinhança" (EIV) do Porto Maravilha, que reúne as principais diretrizes e fundamentos legais da 
intervenção, cuja análise pode ser conferida no primeiro capítulo do presente texto. Analisamos também a Revista Porto Maravilha, de divulgação do andamento das obras (atualmente no seu sétimo número). Estes documentos permitem desenvolver uma perspectiva abrangente das áreas de atuação do Porto Maravilha, bem como os papéis atribuídos às estratégias de preservação histórica e ação cultural. Além da análise de fontes oficiais, serviram também como fontes notícias, reportagens e artigos a respeito do projeto de revitalização e campanhas e canais institucionais de informação (folders, vídeos, sites da prefeitura e rede sociais oficiais dos projetos), em especial quanto ao uso dos valores tipicamente "culturais" para justificar a relevância do projeto. No mesmo sentido, analisamos o conteúdo dos equipamentos culturais em vias implantação, em especial o Museu do Amanhã e o Museu de Arte do Rio.

\section{O Projeto Porto Maravilha}

Nas duas últimas décadas a Prefeitura da Cidade do Rio de Janeiro vem elaborando estudos e projetos de recuperação urbana da região. ${ }^{3}$ Entretanto, tais iniciativas sempre encontraram obstáculos significativos por diversas razões, dentre as quais a ausência do marco legal apropriado e uma série de divergências entre os atores envolvidos - a prefeitura da cidade, que tem a competência de alterar os parâmetros urbanísticos vigentes, o governo do Estado, e as instituições proprietárias de terras da região (especialmente a Companhia Docas do Rio de Janeiro e a Rede Ferroviária Federal). Esta situação começou a mudar quando se formou a aliança entre os governos federal, estadual e municipal, a partir de $2008 .{ }^{4}$

No dia 23 de Julho de 2010, o projeto foi iniciado oficialmente com o evento que reuniu o prefeito Eduardo Paes, o governador Sérgio Cabral e o presidente Luiz Inácio Lula da Silva no cais do porto (local onde será instalado o Museu do Amanhã). Nesse sentido, a

\footnotetext{
${ }^{3}$ Entre 1989 e 1996, o Plano de Desenvolvimento Urbano da Retaguarda do Porto do Rio de Janeiro foi elaborado com o objetivo de "reinserir a área no tecido urbano da cidade", atrair novos empreendimentos privados (serviços, comércio, lazer cultural, e habitação para classe média), além de reintegrar a área à Baía de Guanabara e valorizar o patrimônio arquitetônico e urbano local. Em 1992, é elaborado o "Plano de Estruturação Urbana da Zona Portuária" iniciativa da Secretaria Municipal de Urbanismo e Meio Ambiente com o objetivo de orientar e estimular o tombamento de edifícios históricos a criação de áreas para preservação e reabilitação, o uso habitacional e a reestruturação do sistema viário. Em 1994, foi criado o Projeto Cidade Oceânica do Rio de Janeiro, caracterizado por criação de um pólo de animação cultural e de intercâmbios no Porto, com a construção de centros comerciais, de serviço e de convenções. Em 2001, a prefeitura da cidade definiu como prioridade para a Secretaria de Urbanismo um programa de revitalização da área portuária, desenvolvendo o "Plano de Recuperação e Revitalização da Região Portuária do Rio de Janeiro" (Moreira, 2004).

${ }^{4}$ Vale lembrar que a escolha da cidade para sede da Olimpíada de 2016 e do país para a Copa do mundo de 2014 contribuíram para a formação de um ambiente propício que unisse as instâncias de poder. Com a parceria entre as três esferas de governo, a União, proprietária de $60 \%$ do imóveis da região, os cedeu para o município, inclusive a propriedade do Píer Mauá.
} 
questão fundiária, que engloba as três instâncias de governo foi aos poucos resolvida. Quanto á questão legal, vale notar a importância da elaboração de uma legislação que permitisse a intervenção em grande escala e possibilitasse a alteração dos parâmetros urbanísticos. ${ }^{5}$

Nesse processo de institucionalização da intervenção, um conjunto de críticas e impasses surgiram. Para muitos arquitetos e urbanistas (como Luiz Fernando Janot e Roberto Anderson Magalhães), a proposta de intervenção é simplesmente um "projeto econômico e financeiro" e carece de um projeto urbanístico propriamente dito. Sem dúvida, o Estudo de Impacto de Vizinhança, principal documento da operação urbana que será descrito a seguir, não se caracteriza como "projeto" ou "plano", uma vez que não desenvolve conceitos ou métodos de intervenção e gestão urbana. Trata-se, na realidade, de um estudo que inclui Informações gerais do empreendedor, justificativa e descrição do empreendimento, aspectos legais pertinentes e diagnóstico e prognóstico ambiental da área de influência e da área de intervenção. De acordo com o EIV elaborado pela CDURP $^{6}$, o objetivo da intervenção é conceber um plano completo de revitalização, "de forma que a transforme num novo vetor de crescimento da cidade, como ocorreu com os bairros Copacabana, na década de 1940, Ipanema e Leblon na década de 1960 e com a Barra da Tijuca a partir da década de 1970.” É nesse sentido que, segundo o poder público "O Porto Maravilha é um projeto de requalificação que prevê o reencontro da Região Portuária com a cidade", pois "a degradação presenciada pelos cariocas por décadas na área será revertida em histórica onda de reformas urbanas promovidas pela Prefeitura do Rio". ${ }^{7}$ Da mesma forma, a importância da intervenção é destacada pelo secretário de Desenvolvimento, Felipe Góes: “ [o Porto Maravilha] é um projeto absolutamente estratégico para o futuro de nossa cidade. Resgatar a região portuária é resgatar o Centro do Rio de Janeiro". Assim, o projeto é visto pelo poder público como essencial para o reposicionamento político e cultural da cidade no século XXI. Significativamente, a área de intervenção é vista pelos representantes da prefeitura como um campo de possibilidades para a recodificação da imagem da cidade, um espaço com vocação cultural e econômica para atrair turistas e contribuir para uma transformação econômica do Rio de Janeiro. Por outro lado, tais características naturais precisam ser potencializadas pela

\footnotetext{
${ }^{5}$ Esse objetivo foi alcançado com a aprovação da Lei Municipal Complementar 101 de novembro de 2009 que, em seu primeiro artigo institui a Operação Urbana Consorciada - OUC da região do Porto do Rio de Janeiro, na Área de Especial Interesse Urbanístico (AEIU) "com o objetivo de alcançar transformações urbanísticas estruturais, melhorias sociais e valorização ambiental de parte das Regiões Administrativas I, II, III e VII", que compreendem os Bairros da Saúde, Santo Cristo, Gamboa e Centro.

6 Companhia de Desenvolvimento Urbano da Região do Porto do Rio de Janeiro, gestora da prefeitura do Porto Maravilha.

7 http://www.portomaravilha.com.br/web/esq/imprensa/pdf/05.pdf
} 
intervenção:

[a zona portuária] É a porta de entrada para os turistas que chegam à cidade em cruzeiros e tem em seu interior vários pontos de interesse como a Igreja de São Francisco da Prainha, o conjunto urbano do Morro da Conceição e a recém construída Cidade do Samba. Todos estes aspectos são importantes e apontam uma vocação para um uso da área muito mais intenso do que hoje ocorre com a instalação de novos moradores, comércios, serviços, equipamentos urbanos, culturais, de lazer e grandes parques. Porém, eles não são suficientes por si só, a propiciar a recuperação da área. (CDURP/IPP, 2011, p. 16)

A Figura seguinte, retirada da apresentação do projeto elaborada por Felipe Góis, destaca o papel da intervenção urbana como potencializadora de "vocações existentes" da área.

Figura 1 - Caracterização da Zona Portuária segundo suas "vocações"

\section{A OCUPAÇÃO DO PORTO SERÁ PRIORIZADA ATRAVÉS DO REFORÇO DAS VOCAÇÕES JÁ EXISTENTES EM CADA REGIÃO}

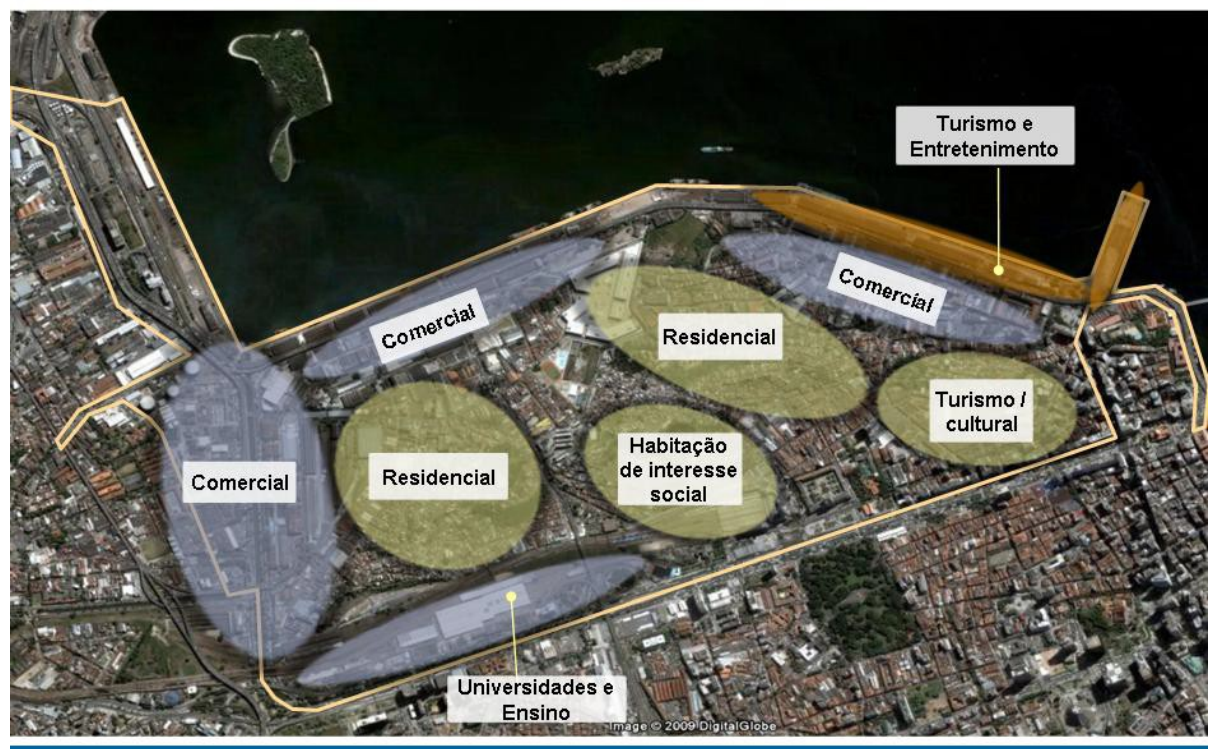

PORTO MARAVILHA $\mid 11$

Fonte: $<$ http://www2.rio.rj.gov.br/smu/compur/pdf/projeto_porto_maravilha.pdf $>$

Considerando que os mapas podem refletir juízos de valor, podemos deduzir que o poder público imagina a área como um espaço determinado pelos seus usos e características naturais, com sentidos e valores ("comércio", "cultura", "habitação") separados e sem relação de influência. Ou seja, não se considera a mistura de usos e funções que geralmente caracteriza áreas históricas. Justifica-se assim, por meio desta e de outras imagens, não apenas o perfil da intervenção mas igualmente uma certa idéia de cidade e da história urbana sem 
conflitos ou contradições sociais. ${ }^{8}$ É curioso notar que a região do Pier, que historicamente possui função econômica e porta de entrada de turistas (o que não a caracteriza necessariamente como área de turismo) é definida como espaço de turismo e entretenimento. Tal classificação dá a impressão de que a intervenção simplesmente moderniza ou potencializa características pré-existentes, mascarando o fato de que o planejamento urbano possui o poder de criar, modificar ou mesmo neutralizar usos e sentidos do espaço urbano.

Cabe destacar também que, geograficamente, a "Zona com vocação para turismo/cultura" (á direita do mapa, próximo á Avenida Presidente Vargas) e a "Zona com vocação para Turismo e entretenimento" (Região do Pier e armazéns 1 a 5) são estratégicas , seja pela sua importância histórica, ou pela visibilidade dessas regiões, por conta da proximidade em relação ás áreas de grande circulação, como a Avenida Rio Branco. Com efeito, o modo de representar a área de intervenção indica o papel preponderante da cultura e da memória urbana na revitalização.

No material analisado, é possível perceber também uma perspectiva essencialista que identifica a cidade como "potência" natural do país, determina certos usos para a zona portuária e naturaliza a relação entre passado e presente. Tal perspectiva é ressaltada pelo arquiteto Antonio Correia ( Secretaria Municipal de Urbanismo), que afirma no primeiro número da Revista Porto Maravilha que:

\begin{abstract}
Não seria exagero afirmar que o Rio de Janeiro domina o Atlântico Sul, sendo o seu porto natural, a referência em qualquer viagem por essas águas. É nesse cenário que a Prefeitura inicia um amplo programa de intervenções urbanísticas, que alterarão significativamente a feição de boa parte do tecido urbano ainda relacionado a usos que outrora eram portuários (armazéns e galpões), possibilitando a renovação dos bairros da Saúde, da Gamboa e do Santo Cristo, extensão natural do Centro da Cidade. Vale destacar que caso deseje, o visitante pode desembarcar e, caminhando à pé, percorrer boa parte do Centro Histórico, conhecendo exemplares da Arquitetura Barroca Brasileira, do casario eclético, do centro financeiro e comercial da cidade. Para tanto, o Rio de Janeiro busca formas de se adaptar às novas demandas, reforçando as suas naturais vocações de cidade cosmopolita e símbolo do país, com o objetivo de tornar como uma experiência única, a simples passagem por aqui! (CORREIA, 2010)
\end{abstract}

É digno de nota o uso implícito de uma noção de capitalidade latino-americana para designar a importância da cidade, além da intenção de produzir uma experiência cultural e histórica singular que depende diretamente do uso estratégico dos marcos culturais da área,

\footnotetext{
${ }^{8}$ Em pesquisa coordenada por Augusto Ivan Pinheiro de Freitas (consultor especial do CDURP na época) e Alex Franulovic da Costa, desenvolveu-se a proposta de dividir conceitualmente a Região Portuária em 11 núcleos homogêneos no sentido de "evidenciar suas peculiaridades e seu potencial de desenvolvimento". Embora caracterize os diferentes espaços de modo mais refinado,considerando a mistura de usos que caracteriza a área, o significado dos marcos urbanos e a sua geografia, a pesquisa continua a evidenciar a importância da "vocação" de cada área (Freitas e Costa, 2011, p. 2).
} 
tendo como modelo outros projetos de recuperação de áreas portuárias. Em sua introdução, o EIV afirma que o objetivo das intervenções é:

(...) transformar a região da zona portuária numa área dinâmica que seja uma nova referência de planejamento urbano para a cidade. Pretende-se seguir o exemplo de cidades ao redor do mundo como Buenos Aires, Nova Iorque, Baltimore e Roterdã, entre outras, que ao recuperarem suas áreas portuárias degradadas, dinamizaram suas economias e ganharam mais um ponto de interesse turístico" (CDURP/IPP, 2010, p 17).

Nota-se nesta argumentação a influência de outras experiências de revitalização, reconhecidas como modelos a serem seguidos, tendo em vista o suposto sucesso dessas intervenções em outras cidades, caracterizadas evidentemente por contextos culturais e problemas sociais muito diferentes. Desconsiderando tais diferenças, os planejadores do Porto Maravilha defendem que o programa de recuperação e reestruturação dos sistemas de infraestrutura urbana permitirá a valorização da região, o aumento de renda para o Estado, a atração de investimentos para "novas unidades residenciais, comerciais e de serviços, sedes de empresas, estabelecimentos hoteleiros, equipamentos culturais e de lazer" e, por fim, a transformação da região da zona portuária numa "área dinâmica que seja uma nova referência de planejamento urbano para a cidade" (CDURP/IPP 2010, p.28). ${ }^{9}$

É nesse sentido que o poder público pretende "valorizar a área central do Rio" e "gerar emprego e renda na cidade" através da revitalização da zona portuária. Trata-se, sem dúvida, de uma proposta ousada, baseada na idéia de que a revitalização da região produzirá um efeito indutor sobre o resto da cidade. ${ }^{10}$ A partir da interpretação dos termos e argumentos utilizados pelos representantes do poder público, podemos deduzir que a região da Praça Mauá e do Píer são espaços estratégicos da revitalização. Sintomaticamente, os equipamentos culturais serão instalados nesta região. Na primeira versão do projeto, a Praça Mauá seria reurbanizada e ampliada até a beira-mar, juntamente com reurbanização da Avenida Rodrigues Alves e Rua Sacadura Cabral. Após a desapropriação por decreto, o Palacete Dom João VI, também na Praça Mauá, seria transformado na Pinacoteca do Estado do Rio em

\footnotetext{
${ }^{9}$ A documentação analisada destaca também a intenção de atrair investimentos para novas unidades residenciais, comerciais e de serviços, sedes de empresas, hotéis, equipamentos culturais e de lazer, fomentar a economia local, alterar o fluxo viário da região e a acessibilidade da área, criar novos espaços públicos e reurbanizar os morros da região. Para estimular o desenvolvimento econômico e social da Região Portuária e revitalizar o patrimônio histórico e ambiental do local, a Operação Urbana Consorciada pretende reforçar a "vocação residencial" da área, recuperando prédios antigos, ocupando terrenos vazios e requalificando áreas de ocupação informal.

${ }^{10}$ A prefeitura pretende aumentar a população da área de 30 mil para 100 mil habitantes nos próximos 10 anos na região. A expectativa de população flutuante deverá atingir 400 mil.
} 
parceria com a Fundação Roberto Marinho. Esse projeto inicial se transformou no Museu de Arte do Rio (MAR).

O Museu do Amanhã, que a princípio se localizaria nos armazéns cinco e seis e no prédio da Polinter, foi realocado no Píer. Segundo o projeto original o Pier seria transformado em um parque que incluiria quiosques, chafarizes e um espaço multiuso. Entretanto, pouco antes de serem iniciadas, as obras do futuro parque no Píer Mauá foram alteradas pela prefeitura da cidade, a partir da proposta do prefeito Eduardo Paes de construir no local "um equipamento público desenhado por um arquiteto de renome internacional”. Esse deslocamento demonstra que o Museu do Amanhã adquire visibilidade e centralidade no processo de revitalização da área, reproduzindo um dos princípios comuns a diversos projetos de revitalização de zonas portuárias: o uso de grandes projetos arquitetônicos monumentais como dinamizadores de desenvolvimento urbano. ${ }^{11}$ Nas palavras do prefeito Eduardo Paes, "Essa aqui é a cereja do bolo. Isso aqui é o ícone maior da revitalização da Zona Portuária. Isso aqui vai ser uma marca nova para essa cidade, como são os Arcos da Lapa, como é o Maracanã, como é o Cristo Redentor. Isso aqui vai ser certamente uma nova marca da nossa cidade". ${ }^{12} \mathrm{O}$ comentário de Paes evidencia o papel central das ações e equipamentos culturais na legitimação do projeto. Cabe, portanto dar foco aos sentidos e funções atribuídas aos investimentos em cultura no Porto Maravilha, objetivo da próxima seção.

\section{Ações culturais no Porto Maravilha}

Embora as ações culturais planejadas para o Porto Maravilha não estejam totalmente concretizadas é possível fazer uma primeira avaliação de suas intenções e de seu papel na legitimação e organização da intervenção urbana. Para tanto é necessário compreender o que entendemos por ação cultural e política cultural. Segundo Teixeira Coelho, uma "ação cultural" se remete aos procedimentos que visam por em prática certa política cultural. Como a ação cultural envolve recurso materiais e humanos diferenciados, pode-se englobar diversas estratégias formulações propostas pela administração pública, organizações nãogovernamentais e empresas privadas, com o objetivo de promover intervenções na sociedade através da cultura e que visam "promover a produção, a distribuição e o uso da cultura, a preservação e divulgação do patrimônio histórico e o ordenamento do aparelho burocrático

\footnotetext{
${ }^{11}$ Nesse mesmo sentido, é digno de nota a proposta do prefeito de transferir a Câmara de Vereadores do Palácio Pedro Ernesto, na Cinelândia, para a zona portuária. O Palácio passaria a abrigar o Museu Histórico da Cidade. 12 http://oglobo.globo.com/rio/municipio-suspende-obra-de-parque-no-pier-maua-3072441 
por elas responsável". A política cultural pode ainda ser entendida como uma "ciência da organização das estruturas culturais" que tem como objetivo "o estudo dos diferentes modos de proposição e agenciamento dessas iniciativas" (COELHO, 1997, p. 292). O que pretendemos nessa seção é compreender os sentidos de tais agenciamentos.

Quanto às intervenções planejadas, sugiro classificar as ações em três vertentes de atuação: a preservação do patrimônio cultural e arqueológico; a instalação de equipamentos culturais e o apoio ou acompanhamento de ações e espaços culturais já existentes na área.

O capitulo 12 do EIV trata da relação entre a paisagem urbana e o patrimônio cultural e arqueológico. A preocupação com o patrimônio da área na qual se insere a operação urbana consorciada (OUC) do Projeto Porto Maravilha "indica o reconhecimento do valor e da importância cultural da região especialmente em termos da formação das primeiras áreas urbanas com funções religiosas militares e residenciais centrais e que depois acompanharam o desenvolvimento das funções portuárias de acesso e comércio", ou seja edificações e ambientes que representam "testemunhos da historicidade do lugares e seu papel fundamental na implantação e evolução urbana da cidade". Esse mesmo capítulo propõe, em suas primeiras páginas, o uso de um conceito supostamente ampliado de patrimônio, ao indicar que este “não se restringe apenas a imóveis oficiais isolados, igrejas ou palácios, mas na sua concepção contemporânea se estende a imóveis particulares, trechos urbanos e até ambientes naturais de importância paisagística, passando por imagens, mobiliário, utensílios e outros bens móveis" (CDURP/IPP 2011, p. 350). Por outro, o texto prende-se ainda ao aspecto material e tangível do patrimônio, pois não há referência explícita ao patrimônio imaterial, nem tampouco ao impacto que tais intervenções podem produzir sobre os equipamentos culturais já existentes, o que seria de esperar de um Estudo de Impacto de Vizinhança.

Se quisermos utilizar a diferença conceitual proposta por CASTRIOTA (2007) entre "preservação", "conservação" e "reabilitação/revitalização", perceberemos que embora a operação consorciada se identifique enquanto "reabilitação" (englobando um discurso que vai além da delimitação de áreas de conservação em direção a um plano de desenvolvimento para área), o capítulo sobre o patrimônio da área prende-se, mesmo que parcialmente, às noções anteriores de preservação (centrado nas ações estatais e legais como o tombamento e no valor estético ou histórico de bens) e conservação dos conjuntos urbanos. 
É verdade que o trabalho de PINHEIRO E COSTA (2011) ameniza em parte essa tendência, ao classificar a área em 11 regiões e destacar os marcos históricos e equipamentos urbanos mais importantes. No entanto, é possível perceber que o Porto Maravilha não reconhece as formas singulares da cultura (no sentido antropológico) da área, e mesmo as referências ao patrimônio local são abordagens técnicas e legais, sem considerar as percepções que os moradores tem desses bens. Cabe lembrar também que não há no EIV um levantamento de equipamentos e ações do local ou diagnóstico sócio-econômico da área. Nesse sentido a preocupação com o patrimônio é justificada simplesmente pelo diferencial cultural e econômico que pode proporcionar. Segundo o EIV:

é possível realizar uma das mais importantes distinções que se pode fazer com relação ao Patrimônio Cultural, pois sendo ele diferente das outras modalidades da cultura restritas apenas ao mercado cultural, apresenta interfaces significativas com outros importantes segmentos da economia como a construção civil e o turismo, ampliando exponencialmente o potencial de investimentos (CDURP/IPP, 2010, p. 350).

O patrimôno é entendido não apenas como forma superior de cultura e expressão de singularidade cultural, mas como um bem criador de rentabilidade em diversos setores da economia. Nesse sentido, no discurso do poder público, a "autenticidade" do patrimônio lhe atribui centralidade na lógica do mercado e do turismo cultural, passando a desempenhar um papel fundamental no desenvolvimento e diferenciação da área. Pode-se arriscar também a hipótese de que tais discursos refletem pouca preocupação com o cotidiano dos moradores e a provável ressonância desse patrimônio sobre a população. Na verdade, a cultura é vista nos documentos oficiais como um conjunto de bens que podem ser utilizados como cenários para atividades culturais, que por sua vez possibilitam não só alguma forma de resgate ou crítica de fatos históricos de determinada sociedade, mas principalmente aquelas que se legitimam pela sua rentabilidade. E estas atividades são rentáveis exatamente porque funcionam como ornamentos pessoais, modos de afirmação social, formas de entretenimento, ou fontes de atualização e/ou informação - e que provocam em última análise algum tipo de "gratificação psíquica”, distinção sócio-econômica ou, simplesmente, ocupação lúdica (HUYSSEN 2000, ARANTES 2000). Essas narrativas sugerem a idéia de que cultura e patrimônio são modos de expressar uma nova identidade urbana, cujo efeito é a criação de mensagens sobre os encantos da vida local. É este contexto que justifica o uso de um planejamento estratégico, que evoque um sentimento de "civismo" em relação à cidade (SANCHEZ 2001). A questão é que ao ver a cultura e patrimônio como fator de união e 
consenso, em uma espécie de "uso cívico" das ações culturais (tanto no plano ideologico quanto nas intervenções objetivas) omite-se as tensões que constituem a dimensão cultural, isto é, como campo de disputa por legitimidade de diversos grupos e instâncias de poder. O discurso oficial não considera tambem que a memória é sempre transitória e passível de esquecimento (HUYSSEN 2000) e que o patrimônio pode ser entendido na contemporaneidade como um sinal de ruptura e não de coesão social (HARTOG 2006).

Quanto á instalação de equipamentos culturais, destacam-se os papéis do Museu do Amanhã e do Museu de Arte do Rio. O Museu do Amanhã já foi apresentado por diversas autoridades e em diversas situações como o "ícone da reurbanização" da Zona Portuária. No texto chamado "Obras por todos os lados", publicado na sexta edição da Revista Porto Maravilha, é destacado o papel central do museu na revitalização da região: "Esse é um grande símbolo dessa requalificação. Representa uma cidade que resgata e respeita o passado, vislumbrando o futuro". Idealizado pela fundação Roberto Marinho, a exemplo dos museus da Língua Portuguesa e do Futebol em São Paulo, o museu será construído em uma área estratégica, o Pier Mauá. O museu tem a assinatura de Santiago Calatrava, arquiteto de renome internacional ${ }^{13}$ e sua monumentalidade e posição geográfica evidenciam o papel central que o equipamento cultural desempenha no reforço da identidade da cidade.

Segundo Leonel Kaz, um dos seus curadores, o Museu do Amanhã deve ser caracterizado como um "museu-experiência": "Um museu experiência não significa uma experiência apenas do conhecimento, mas também de transformação, de percepção sensível, quando o visitante é estimulado a dialogar com o espaço o tempo todo". Podemos deduzir que o termo "experiência" é utilizado como uma percepção sensorial singular e marcante, estimulada pelo uso de novas tecnologias da comunicação cuja intenção é apresentar a trajetória do homem no planeta e o seu impacto sobre a natureza. O projeto do museu propõe um novo modelo de "museu de ciências", evitando tanto o foco na história natural, isto é, no passado (como os museus de história natural) quanto a preocupação única com a ciência e a tecnologia do presente (como os museus que lidam com evidências e experiências científicas). Sua intenção é conscientizar o visitante do seu papel na construção do futuro, como expressa a apresentação do museu encontrada no site do projeto:"por meio de ambientes

\footnotetext{
${ }^{13}$ Entre seus projetos mais famosos, podemos citar o Complexo Olímpico de Atenas, a Estação do Oriente em Lisboa, Portugal; a Cidade das Artes e das Ciências em Valência, Espanha; o Stadelhofen Railway Station em Zúrique, Suíça e o Museu de Arte de Milwaukee, EUA. Assim como Frank Gehry (autor do Museu Gugenheim de Bilbao) e o holandês Rem Koolhaas (do Museu Gugenheim de Las Vegas), seus projetos se caracterizam por provocarem uma transformação radical no cenário urbano.
} 
audiovisuais, instalações interativas e jogos, o público será levado a examinar o passado, manipular as várias tendências da atualidade e imaginar futuros possíveis para os próximos 50 anos".

Neste ponto, vale destacar a diferenciação e as possíveis relações do Museu do Amanhã e a diferenciação conceitual entre "museu-narrativa" e "museu informação", proposta por GONÇALVES (2003). Segundo esse autor, "museu-narrativa", se refere ao museu na acepção tradicional do termo, preocupado com a autenticação e apresentação de objetos selecionados pelo seu poder de evocar o passado. Por seu turno, o "museuinformação" valoriza o poder comunicativo de idéias e valores em detrimento da continuidade e da autenticidade dos objetos do passado. Tais instituições se caracterizam por relativizar a importância dos objetos, vistos mais como "suportes materiais de idéias abstratas, como ilustrações dos textos; e menos como objetos a serem apreciados em si mesmos (....)". Podemos supor que o Museu do Amanhã possuirá algumas das características do modelo museu-informação:

(...) o conjunto de ideias e valores a que chamo de museu-informação desenvolvem-se em função das grandes metrópoles e de suas multidões anônimas, definindo-se a partir de suas relações com o mercado, com um público vasto voltado para o consumo de informações e bens culturais. Ele existe para atender a esse público, e pelo qual se vê na contingência de competir com os meios de comunicação de massa" (GONÇALVES 2003, p. 182-3)

Talvez seja possível perceber nas propostas desse museu características que transcendem "narrativa" e "informação". Como lembra em entrevista ao autor um dos responsáveis pela mediação entre os curadores e o conselho consultivo:

Porque como ele [o museu] não é um museu nem de "vestígios" - que não é de acervo histórico - como ele também não é um museu de demonstrações que ele não é um museu de ciências per se, que quer demonstrar gravidade ou efeitos óticos nem nada disso, ele é um museu de narrativa, um museu que quer apresentar essas diferentes possibilidades do amanhã, então a gente na verdade puxa os elementos que condizem com a história, a narrativa que a gente quer traçar.

Compreende-se que o Museu do Amanhã proporá não mais uma narrativa baseada em objetos mas sim uma relação de causalidade entre passado presente e futuro, através do caminho proposto no interior do museu, das "origens do universo" até o "futuro". Nesse sentido, a "experiência" do museu se remete aos estímulos sensoriais, provocados através de tecnologias interativas e de exposições que articulem aspectos tecnológicos, artísticos e 
científicos. Esse "fio narrativo" indica um processo de valorização dos textos e imagens em detrimento dos objetos (também característica do "museu-informação") e parece estar subordinado ao poder de comunicar ideias, produzir um impacto sensorial e propor de um conjunto de questões sociais e ambientais ao espectador (Figura 2). Segundo o curador Luiz Alberto Oliveira durante a apresentação do projeto, ocorrido dia 2 de maio, no Palácio da Cidade,

Estamos propondo outra geração de museu, o de perguntas e de explorações de possibilidades. Essa é a grande coleção desse espaço. Para transformar o nosso pensamento, para mudar o nosso comportamento e para abrir a nossa mente. É um conteúdo científico para desafiar a mente, uma abordagem artística para envolver os nossos sentidos e uma interpretação cultural da ciência para tocar as nossas emoções.

Figura 2 - Imagem virtual da exposição central do Museu do Amanhã

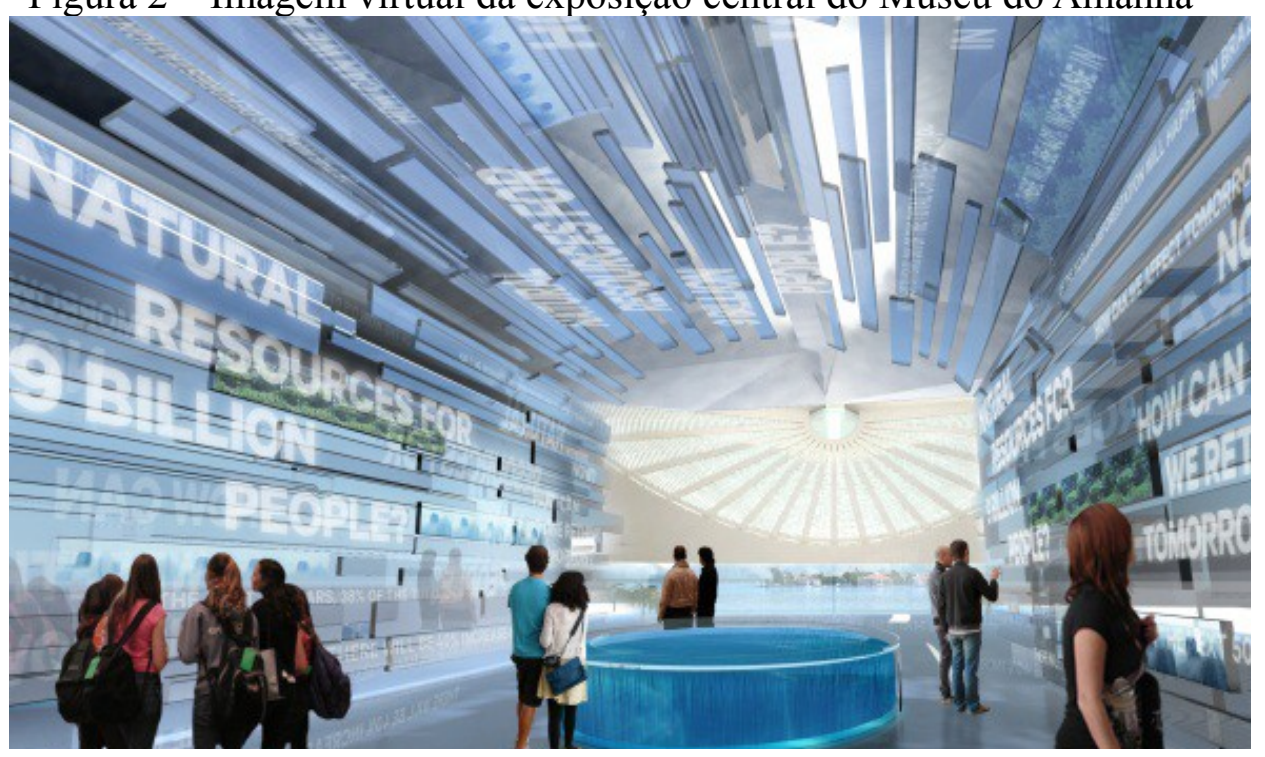

Fonte: http://portomaravilha.com.br/web/esq/imprensa/pdf/16.pdf

Se o Museu do Amanhã se enquadra no modelo dos novos museus situados em edificações vistas como "marcas" emblemáticas que inscrevem a cidade no roteiro da arquitetura internacional, o Museu de Arte do Rio (MAR) segue outra vertente muito em voga na revitalização de centros históricos: a reutilização de prédios preexistentes que são reintegrados ao contexto urbano por meio do uso cultural. O Museu de Arte do Rio será instalado em dois prédios de estilos e origens diferentes - o Palacete Dom João VI (também conhecido como Palacete Mauá) de estilo eclético, e o edifício vizinho, no prédio modernista, onde funcionava um hospital da Polícia Civil, cedido pelo governo do Estado. O Palacete 
abrigará as salas de exposição do museu enquanto o prédio vizinho vai abrigar a Escola do Olhar, apresentado como um espaço com foco na formação de educadores da rede pública de ensino. Como no caso do Museu do Amanhã, esses equipamentos são desenvolvidos em parceria com a Fundação Roberto Marinho. Os dois prédios que formam a instituição serão unidos por meio de uma passarela envidraçada.

Apesar de não estar claro até o momento o projeto de conteúdo do museu, é possível desenvolver uma análise preliminar de seus princípios e propostas, isto é , de sua concepção curatorial. ${ }^{14}$ Podemos destacar ao menos duas características do futuro museu. Em primeiro lugar, trata-se de um museu de arte, com ênfase na dimensão informativa e pedagógica. A curadoria pretende aproveitar o acervo e artístico da cidade, divulgando-o aos estudantes do ensino público por meio da Escola do Olhar, a partir de parceria com a Secretaria Municipal de Educação do Rio de Janeiro. Segundo Kaz, a proposta do Museu é "interligar o olhar dos estudantes e professores com o de colecionadores", com exposições e projetos educativos que reúnam diversos suportes e formas culturais, como moda, design, cinema, entre outras:

Como recomenda a UNESCO, o MAR terá atividades que envolvem coleta, registro, pesquisa, preservação e devolução à comunidade de bens culturais - sob a forma de exposições, catálogos, programas em multimeios e educacionais. Com sua própria coleção - já em processo de formação por meio de aquisições e doações correspondentes à sua agenda - o MAR contará também com empréstimos de obras de algumas das melhores coleções públicas e privadas do Brasil para a execução de seu programa. $^{15}$

Em segundo lugar, o museu propõe uma releitura da história da cidade. O discurso do MAR sinaliza uma tentativa de reagir à perda da centralidade da cidade através do que poderíamos chamar de "poder redentor" da cultura. Não é por outra razão que Leonel Kaz enfatize o papel do museu na recuperação da centralidade da cidade: "Precisamos recuperar a vitalidade do Rio e da Região Portuária, reconquistando este território da cidade em benefício da cultura". Embora não fique claro o que se entende por cultura no caso (cultura como valor? o patrimônio cultural local?) podemos detectar a preocupação com as "relíquias" e objetos de valor artístico, no sentido de recuperar uma autenticidade da cultura carioca, como demonstra a apresentação do museu no blog do Porto Maravilha: “As exposições do MAR vão mostrar o

\footnotetext{
${ }^{14}$ A concepção curatorial envolve a definição dos eixos centrais a partir dos quais os objetos, imagens e textos serão expostos. Ou seja, trata da elaboração dos conceitos fundadores das exposições e seus objetivos. Já o projeto de conteúdo realizará a concepção museográfica preliminar, a definição do acervo a ser exposto para cada temática, a realização da pesquisa de acervo e a construção e catalogação desses acervos. ${ }_{15}$ Disponível em < portomaravilha.com.br/web/esq/projEspMAR.aspx >
} 
Rio através da Arte, como nenhum carioca jamais viu. Fotos raras, relíquias impensadas, famosos acervos de grandes colecionadores e tudo mais que traduz a cidade do Rio de Janeiro estará lá". ${ }^{16}$

A criação do MAR é um caso clássico no qual a patrimonialização e a refuncionalização de edificações com "valor histórico" é utilizada como forma de ressemantização de uma área degradada. Em outras palavras, a requalificação dos edifícios transformados em equipamento cultural teria a função de criar não apenas um novo olhar sobre o entorno, mas igualmente uma forma específica de intervenção sobre a região e sobre a história local. A apresentação do museu presente no site oficial do Porto Maravilha vai além ao propor que o conteúdo do Mar possibilitaria uma revisão da história da cidade.

\footnotetext{
O Museu de Arte do Rio (MAR) pretende promover uma leitura transversal da história da cidade, seu tecido social, sua vida simbólica, conflitos, contradições, desafios e expectativas sociais. Suas exposições vão unir dimensões históricas e contemporâneas da arte por meio de mostras de longa e curta duração, de âmbito nacional e internacional.
}

Não se trata aqui de levantar questões a respeito do futuro da cidade e do ser humano como no caso do Museu do Amanhã, mas de revisar e resgatar o passado da cidade, articulando-o ao presente e fortalecendo nesse processo a identidade local. É razoável pensar que o museu desenvolverá um discurso de autenticidade (cujo caráter construído geralmente é mascarado) a respeito da cultura local, legitimando certos valores sociais e estilos estéticos. Por outro lado, há também uma preocupação com a divulgação, pesquisa e comunicação, na medida em que o museu visa dar visibilidade ao patrimônio urbano e dialogar com o cotidiano da cidade.

Por fim, cabe lembrar a incorporação de determinados equipamentos e marcos da história local, que têm passado nos últimos meses por um processo de assimilação pelo Porto Maravilha que implica na restauração de edificações e elaboração de circuitos culturais. Os "marcos históricos" da região não são valorizados com a mesma intensidade pelas intervenções do Porto Maravilha, o que ressalta o caráter seletivo de qualquer intervenção ou regeneração urbana. Alguns elementos históricos, como o antigo Cais do Valongo, descoberto durante as escavações na Av. Sacadura Cabral foi incorporado como memorial a céu aberto. Em 16 de novembro de 2011 foi criado, por meio do Decreto $\mathrm{n}^{\circ} 34.803$, de 29 de novembro, o

16 Disponível em < $\mathrm{http}$ ://blogportomaravilha.com/2011/05/30/escola-do-olhar/> 
Circuito Histórico e Arqueológico da Celebração da Herança Africana, que compreende o Cais do Valongo e da Imperatriz, os Jardins do Valongo, a Pedra do Sal, o Largo do Depósito, o Cemitério dos Pretos Novos (no Instituto dos Pretos Novos) e o Centro Cultural José Bonifácio (sede do Centro de Referência da Cultura Afro-brasileira). ${ }^{17}$ Essa região foi, a princípio, pensada como "Memorial da diáspora africana" (reivindicação de certos segmentos do movimento negro), foi remodelada como "circuito turístico", o que parece esvaziar a tentativa inicial de transformar a área em espaço de resistência ou problematização das identidades culturais.

Diante do exposto, podemos compreender a noção de revitalização cultural de centros urbanos e zonas portuárias a partir de suas estratégias de resgate histórico, desenvolvimento econômico e resemantização das identidades urbanas. Neste artigo, procuramos mostrar alguns dos sentidos atribuídos à cultura e ao patrimônio no contexto do Porto Maravilha. Tais sentidos são, evidentemente, elaborados dentro de relações sociais e políticas especiais e podem ser transformados, enfatizados ou neutralizados de diversas maneiras. Esse contexto lança questões e desafios à compreensão dos novos sentidos atribuídos a categorias como "patrimônio urbano", "centro histórico", "coleções", "monumento", "identidade", entre outros. Embora a noção de "cultura" seja utilizada pelos agentes do poder público como um espaço de consenso e união, talvez seja interessante evidenciar que os projetos de revitalização como um campo de disputa, caracterizado por estratégias de legitimação e deslegitimação de noções específicas de cultura e memória.

\section{Referencias Bibliográficas:}

ARANTES, Otília. "Uma Estratégia Fatal: A cultura nas novas gestões urbanas". In: Otília Arantes, Carlos Vainer, Ermínia Maricato (Orgs.), A Cidade do Pensamento Único: Desmanchando Consensos. Rio de Janeiro: Vozes, 2000, p. 11-74.

BROUDEHOUX, Anne-Marie. "La régénération par la culture, les grands projets culturels et la spectacularisation du paysage urbain à l'ère du néolibéralisme mondial”. 2010. Cópia reprográfica.

\footnotetext{
${ }^{17} \mathrm{O}$ decreto também instituiu um grupo de trabalho, sob a coordenação da Subsecretaria de Patrimônio Cultural do município, Secretaria Municipal de Cultura, Secretaria de Políticas de Promoção da Igualdade Racial (Seppir), Companhia de Desenvolvimento Urbano da Região do Porto do Rio de Janeiro (Cdurp) e Iphan, além de intelectuais e representantes de organizações locais e lideranças como o embaixador Alberto Costa e Silva, Giovane Harvey e Milton Guran (representante da Unesco que integra equipe responsável pelo mapeamento de locais que representem o período da escravidão).
} 
Carta de Lisboa sobre reabilitação urbana integrada. In: $1^{\circ}$ Encontro Luso-Brasileiro de Reabilitação Urbana Lisboa, 1995.

CASTRIOTA, Leonardo. "Intervenções sobre o Patrimônio construído: Modelos e Perspectivas". Forum Patrimônio. Belo Horizonte, v .1, n .1 ,set . /dez . 2007

CDURP/IPP. Estudo de Impacto de vizinhança d a Operação Urbana Consorciada da Região do Porto do Rio. Disponível em http://www.portomaravilha.com.br/eiv/

CORREIA, Antônio. "Rio de Janeiro - Cidade do Atlântico Sul”. Revista Porto Maravilha, $\mathrm{n}^{\mathrm{o}} 1$, março de 2010, p. 7.

COSTA, Pedro. "A Fileira das Atividades Culturais e a Economia Urbana". In: I Congresso Português de Sociologia Econômica. Maio de 1998.

DEL RIO, Vicente. Voltando às origens. "A revitalização de áreas portuárias nos centros urbanos". Arquitextos, São Paulo, Agosto de 2001. Disponível em

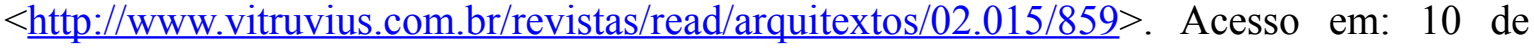
outubro de 2010.

FERRARA, Lucrécia D’alessio. "Cidade: Imagem e imaginário". In: Weyrauch, Cleia Schiavo (Orgs.) Três visões de cidade. Rio de Janeiro, Rio de Janeiro: UERJ, Departamento cultural, 2000, p. 11-27.

FERREIRA, Alvaro. "O projeto "Porto Maravilha" no Rio de Janeiro: inspiração em Barcelona e produção a serviço do capital ?". Biblio 3W. Revista Bibliográfica de Geografía y Ciencias Sociales, Vol. XV, no 895 (21). Barcelona: Universidade de Barcelona, Novembro de 2010.

GONÇALVES, José Reginaldo Santos. "Os Museus e a Representação do Brasil”. In: Antropologia dos objetos: coleções, museus e patrimônios. Rio de Janeiro: Departamento de Museus e Centro Culturais, 2007.

"Monumentalidade e cotidiano: os patrimônios culturais como gênero de discurso". In: Cidade: história e desafios. Lucia Lippi Oliveira, organizadora. Rio de Janeiro: FGV, 2002, p. 108-123.

HARTOG, François. “Tempo e patrimônio”. Varia hist., Dez 2006, vol.22, n. 36, p.261-273.

HUYSSEN, Andreas. Seduzidos pela memória. Rio de Janeiro: Aeroplano Editora, 2000.

MOREIRA, Clarissa da Costa. A cidade contemporânea entre a "tabula rasa" e a preservação: cenários para o Porto do Rio de Janeiro. São Paulo: Unesp, 2004.

PEIXOTO, Paulo. "Centros históricos e sustentabilidade cultural das cidades". In: Colóquio A cidade entre projectos e políticas. Faculdade de Letras da Universidade do Porto, 30 de Junho de 2003.

PINHEIRO, Augusto e COSTA, Alex. "Região Portuária: uma proposta de divisão em núcleo. 
2011. Disponível em http://www.portomaravilha.com.br/web/direito/conhecaRegiao.aspx.

SANCHEZ, Fernanda. "A reinvenção das cidades na virada de século: Agentes, estratégias e escalas de ação política". Revista de sociologia política, n. 16, p. 31-49. Curitiba: UFPR, jun. 2001.

Secretario fala sobre Porto Maravilha. Disponível em

$<$ http://www.rio.rj.gov.br/web/smu/exibeconteudo?article-id=1132990 $>$ acesso em $16 / 09 / 2010$

Prefeitura da Cidade do Rio de Janeiro. Lei Municipal complementar n. 101/2009. Disponível em http://www.portomaravilhario.com.br/media/legislacao/2010/06/LC101__23112009.pdf

"Porto Maravilha - o projeto". Disponível em

http://www.portomaravilha.com.br/web/esq/imprensa/pdf/05.pdf

\title{
CULTURE, HERITAGE AND MUSEUMS IN "PORTO MARAVILHA"
}

\begin{abstract}
This study discusses the meanings and functions of the proposed actions on cultural revitalization project of the Port Zone of Rio de Janeiro, called "Porto Maravilha". I emphasize the relationship between the city, memory and culture of the city. First, we describe the Marvelous Port project, critically considering their goals and the type of city conception. Then, we present the main cultural shares present at the operation, highlighting the cultural heritage preservation and installation of museums in the area.
\end{abstract}

KEYWORDS: Urban revitalization, heritage, museums. 